\title{
Study on the diversity of epiphytic bacteria on corn and alfalfa using Illumina MiSeq/ NovaSeq high-throughput sequencing system
}

Meixiao Wu ${ }^{1,2}$, Yuehua Wang ${ }^{1,2}$, Yijing Wang ${ }^{1,2}$, Xuefei Wang ${ }^{3}$, Ming Y Y ${ }^{3}$, Guixia Liu ${ }^{1,2^{*}}$ and Hui Tang ${ }^{1,2^{*}}$ (1)

\begin{abstract}
Purpose: To investigate the diversity of the epiphytic bacteria on corn (Zea mays) and alfalfa (Medicago sativa) collected in Hengshui City and Xingtai City, Hebei Province, China, and explore crops suitable for natural silage.

Methods: The Illumina MiSeq/NovaSeq high-throughput sequencing system was used to conduct paired-end sequencing of the community DNA fragments from the surface of corn and alfalfa collected in Hengshui and Xingtai. QIIME2 and R software were used to sort and calculate the number of sequences and taxonomic units for each sample. Thereafter, the alpha and beta diversity indices at of species level were calculated, and the abundance and distribution of taxa were analyzed and compared between samples.

Result: At phylum level, the dominant groups were Proteobacteria (70\%), Firmicutes (13\%), Actinobacteria (9\%), and Bacteroidetes (7\%). Meanwhile, the dominant genera were Pseudomonas (8\%), Acinetobacter (4\%), Chryseobacterium (3\%), and Hymenobacter (1\%). Enterobacteriaceae (24\%) were the most predominant bacteria in both the corn and alfalfa samples. Alpha diversity analysis and beta diversity indices revealed that the diversity of epiphytic microbial communities was significantly affected by plant species but not by region. The diversity and richness of the epiphytic bacterial community of alfalfa were significantly higher than those of corn.
\end{abstract}

Conclusion: This study contributes to the expanding knowledge on the diversity of epiphytic bacteria in corn and alfalfa silage and provides a basis for the selection of raw materials.

Keywords: Bacterial diversity, Alfalfa, Corn

\section{Introduction}

Natural silage is the process of converting the fermentation substrate (soluble sugar) in raw materials into acidic products, such as lactic acid through the proliferation of lactic acid bacteria (LAB) on crops. This process creates an acidic environment and inhibits the proliferation of harmful microorganisms, thereby preserving the nutritional content of raw materials (Zhang et al. 2011). As a storage technology, silage reduces forage nutrient loss,

\footnotetext{
* Correspondence: liuguixia1971@163.com; tangshude1234@163.com

${ }^{1}$ School of Life Sciences, Hebei University, Baoding 071002, People's Republic of China

Full list of author information is available at the end of the article
}

facilitates animal digestion and absorption, increases the value of forage utilization, expands the source of forage, and adjusts the forage supply period (Shang et al. 2019). After silage, the nutrients will not be reduced. Silage also has an aromatic and sour taste, which stimulates the appetite of livestock and increases feed intake. The quality of natural silage was greatly affected by the epiphytic microflora on crops. The fermentation time of natural silage is very long. LAB cannot form dominant bacteria in a short time. Therefore, the crops with high LAB and low epiphytic microbial diversity should be more suitable for natural silage.

(c) The Author(s). 2021 Open Access This article is licensed under a Creative Commons Attribution 4.0 International License, which permits use, sharing, adaptation, distribution and reproduction in any medium or format, as long as you give appropriate credit to the original author(s) and the source, provide a link to the Creative Commons licence, and indicate if changes were made. The images or other third party material in this article are included in the article's Creative Commons licence, unless indicated otherwise in a credit line to the material. If material is not included in the article's Creative Commons licence and your intended use is not permitted by statutory regulation or exceeds the permitted use, you will need to obtain permission directly from the copyright holder. To view a copy of this licence, visit http://creativecommons.org/licenses/by/4.0/. 
Studies have observed that LAB, such as Lactobacillus, Lactococcus, Leuconstoc, Streptococcus, Pediococcus, and Enterococcus, play a key role during the silage fermentation processing (Gharechahi et al. 2017). The abundance of LAB on crops determines the success of the silage process. Depending on the production of metabolites, LAB can be divided into two groups: homofermentative $\mathrm{LAB}$ and heterofermentative LAB. Homofermentative LAB can produce more lactic acid, which can improve the fermentation quality of silage. Moreover, they produce volatile fatty acids to inhibit the growth of aerobic bacteria and improve the aerobic stability of silage.

The epiphytic microflora greatly affects the quality of natural silage fermentation. And the fermentation quality of silage can be affected by different crops or even the same crop grown under different environments conditions (Ali et al. 2020; Huang et al. 2019). Choosing the appropriate forage ingredients can help improve the quality of the silage. Corn (Zea mays) and alfalfa (Medicago sativa) are often utilized to produce silage. Identifying the epiphytic microflora on forage can provide a scientific basis for effectively regulating the fermentation process of silage. The population of eubacteria on corn samples collected immediately was mainly composed of genera belonging to Proteobacteria $(56.4 \pm 1.5 \%)$, specifically to orders Pseudomonadales, Xanthomonadales, and Enterobacteriales; and Bacteriodetes $(37.4 \pm 1.7 \%)$, specifically to orders Sphingobacteriales and Flavobacteriales (Drouin et al. 2019). Lactobacillales were substantial contributors of Firmicutes, with Leuconostocaceae representing between $60 \%$ and $100 \%$ of the fresh forage sample composition (Drouin et al. 2019). Enterobacteriaceae are predominant on corn and alfalfa (Lin et al. 1992). Yeasts and moulds are also major epiphytic microorganisms on both crops (Lin et al. 1992; Zhang 2011). However, the abundance of LAB on the raw material for ensiling is far less than that of aerobic bacteria, Escherichia coli, yeast, mould, and other harmful microorganisms (Zhang et al. 2011). The number of $L A B$ on the surface of corn was greater than that of other raw materials (Cai et al. 1999; Kasmaei et al. 2017). However, there are few reports on the epiphytic microorganisms on corn and alfalfa. This study discussed the species and diversity of epiphytic bacteria on corn and alfalfa.

\section{Materials and methods Collection of samples}

Samples were collected in the budding to the early flowering stage of alfalfa, and in the late milking to the early waxing stage of corn. Alfalfa and corn samples were collected in Xingtai $\left(113^{\circ} 52^{\prime} \mathrm{E}, 36^{\circ} 50^{\prime} \mathrm{N}\right)$ and Hengshui $\left(115^{\circ} 10^{\prime} \mathrm{E}, 37^{\circ} 04^{\prime} \mathrm{N}\right)$, Hebei Province. The moisture content was approximately $50 \sim 60 \%$. The specific sampling results are presented in Table 1.

\section{Sample DNA extraction and PCR amplification, quantification, pooling and sequencing}

DNA was extracted using the E.Z.N.A. Soil DNA Kit (Omega Bio-tek, Norcross, GA, USA) according to the manufacturer's protocols, and quantified using Nanodrop. The quality of DNA extracted was observed through electrophoresis on a 1.2\% agarose gel. The variable region of the $16 \mathrm{~S}$ rRNA gene (single or consecutive multiple) or specific gene fragments was amplified using polymerase chain reaction (PCR). Subsequently, the PCR products were purified using Vazyme VAHTSTM DNA Clean Beads and quantified fluorometrically. Sequencing libraries were prepared using Illumina TruSeq Nano DNA LT Library Prep Kit. PCR products that met the minimum concentration required for analysis were electrophoresed in $2 \%$ agarose gel to check for the correct size of the target bands. High-throughput sequencing was conducted using Illumina Miseq/NovaSeq at Personalbio Company (Shanghai, China).

\section{Bioinformatics and statistical analysis}

Bioinformatics was mainly performed using QIIME2 (2019.4) (Bolyen et al. 2018). Sequences were denoised using the DADA2 plugin (Callahan et al. 2016). Instead of clustering by similarity, DADA2 only performs dereplication or clustering at $100 \%$ similarity. Because DADA2 has not yet been adapted to all amplicons, we retained the OTU clustering-based Vsearch (Rognes et al. 2016) as an alternative. The abundance, distribution, alpha, and beta diversity indices were analyzed using QIIME2 and R software (Xie et al. 2016). The accession numbers for sequencing data presented is PRJNA745034.

\section{Results}

Species composition analysis

The specific composition of the microbial communities at each classification level in each sample was obtained using the statistics of the amplicon sequence variant (ASV) table after rarefaction. The ggplot2 package in $\mathrm{R}$ (Ginestet 2011) was used to plot the data and generate a histogram to visualize the number of taxa at each classification level in the samples (Fig. 1). A microbial classification hierarchy tree was also generated to reveal the composition of all taxa at the same time using $\mathrm{R}$ language ggtree package (Yu et al. 2017).

At phylum level, Proteobacteria (70\%), Firmicutes (13\%), Actinobacteria (9\%), and Bacteroidetes (7\%) were the most dominant (Fig. 2). The four phyla have more branches in the tree, which indicates that the genotypes 
Table 1 Origin and grouping of microbial samples

\begin{tabular}{|c|c|c|c|c|c|c|}
\hline Places & Plants & Breed & Serial number & Groups & & \\
\hline \multirow[t]{7}{*}{$\overline{\text { Xingtai }}$} & Corn & Jinchu 100 & D1 & D1-1 & D1-2 & D1-3 \\
\hline & & Duobao No. 3 & D2 & D2-1 & D2-2 & D2-3 \\
\hline & & Shengrui 565 & D3 & D3-1 & D3-2 & D3-3 \\
\hline & & Yawangqingchu No. 8 & D4 & D4-1 & D4-2 & D4-3 \\
\hline & Alfalfa & SR4030 & E1 & E1-1 & E1-2 & E1-3 \\
\hline & & Saidi 5 & E2 & E2-1 & E2-2 & E2-3 \\
\hline & & Zhongmu No. 1 & E3 & E3-1 & E3-2 & E3-3 \\
\hline \multirow[t]{7}{*}{ Hengshui } & Corn & Duobao No. 3 & F1 & F1-1 & F1-2 & F1-3 \\
\hline & & Shengrui 565 & $\mathrm{~F} 2$ & F2-1 & $F 2-2$ & $F 2-3$ \\
\hline & & Jinchu 100 & F3 & F3-1 & F3-2 & F3-3 \\
\hline & & Yawangqingchu No. 8 & F5 & F5-1 & F5-2 & F5-3 \\
\hline & Alfalfa & SR4030 & G1 & G1-1 & G1-2 & G1-3 \\
\hline & & Zhongmu No. 1 & G2 & G2-1 & $\mathrm{G} 2-2$ & G2-3 \\
\hline & & Saidi 5 & G5 & G5-1 & G5-2 & G5-3 \\
\hline
\end{tabular}

of the dominant bacteria in the samples are diversified in evolutionary relations. Interestingly, Lactobacillales was more abundant in corn samples than in alfalfa samples (Fig. 2). Enterobacteriaceae (24\%), which belongs to Proteobacteria, was the most predominant family in both corn and alfalfa samples. Four genera have more than $1 \%$ of the reads and they are Pseudomonas (8\%), Acinetobacter (4\%), Chryseobacterium (3\%), and Hymenobacter (1\%) (Figs. 2 and 3).

\section{Microbial diversity analysis of corn and alfalfa samples} Alpha diversity analysis

Alpha diversity represents the diversity of species within a habitat. Chao1 species index measures the species richness within a community (Chao 1984), while Shannon and Simpson indices measure the species diversity within a community (Simpson 1949). Observed species indices measure community richness. Phylogenetic diversity (PD) index represents diversity based on

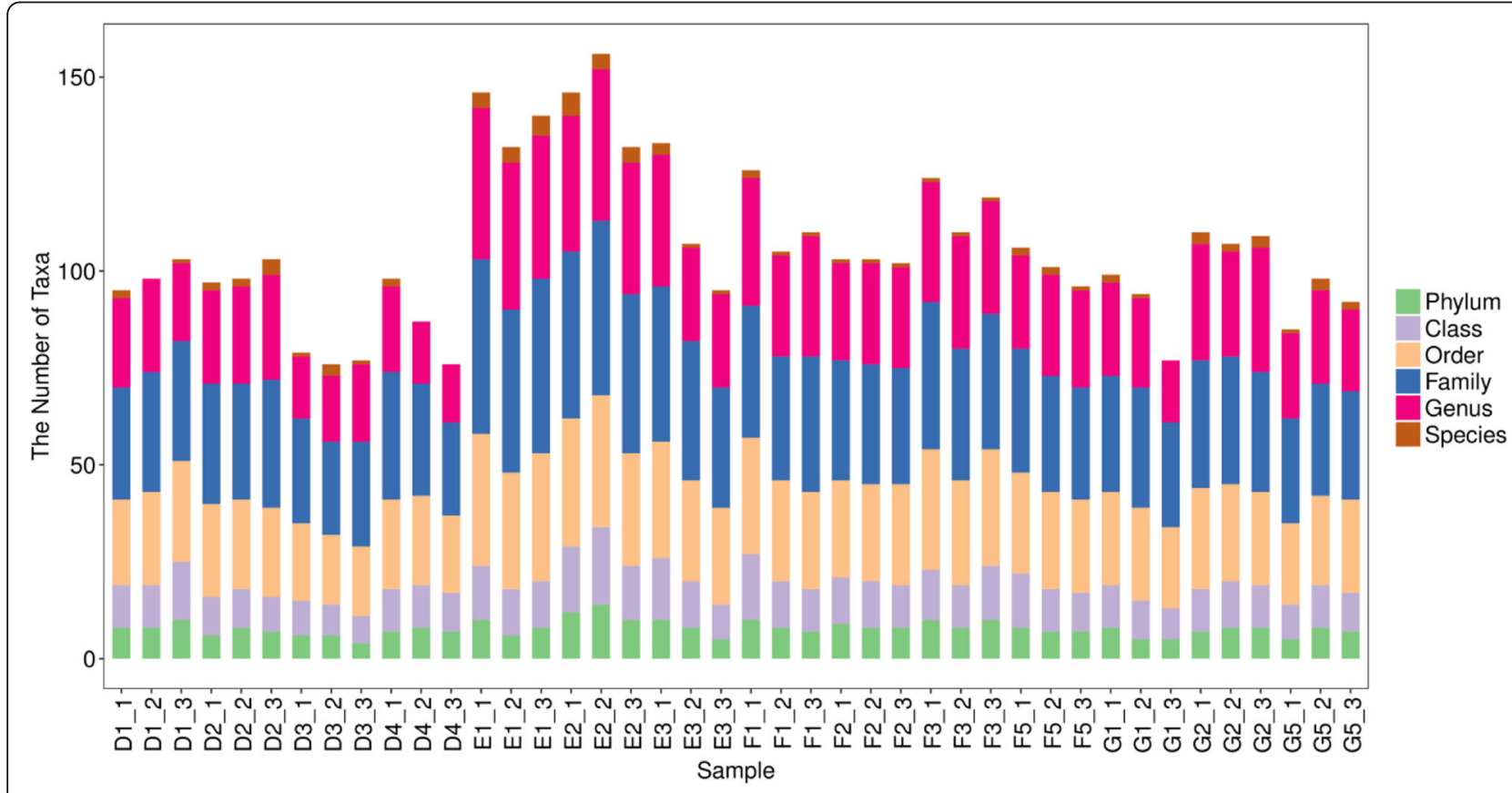

Fig. 1 The number of taxa at each classification level for different samples 


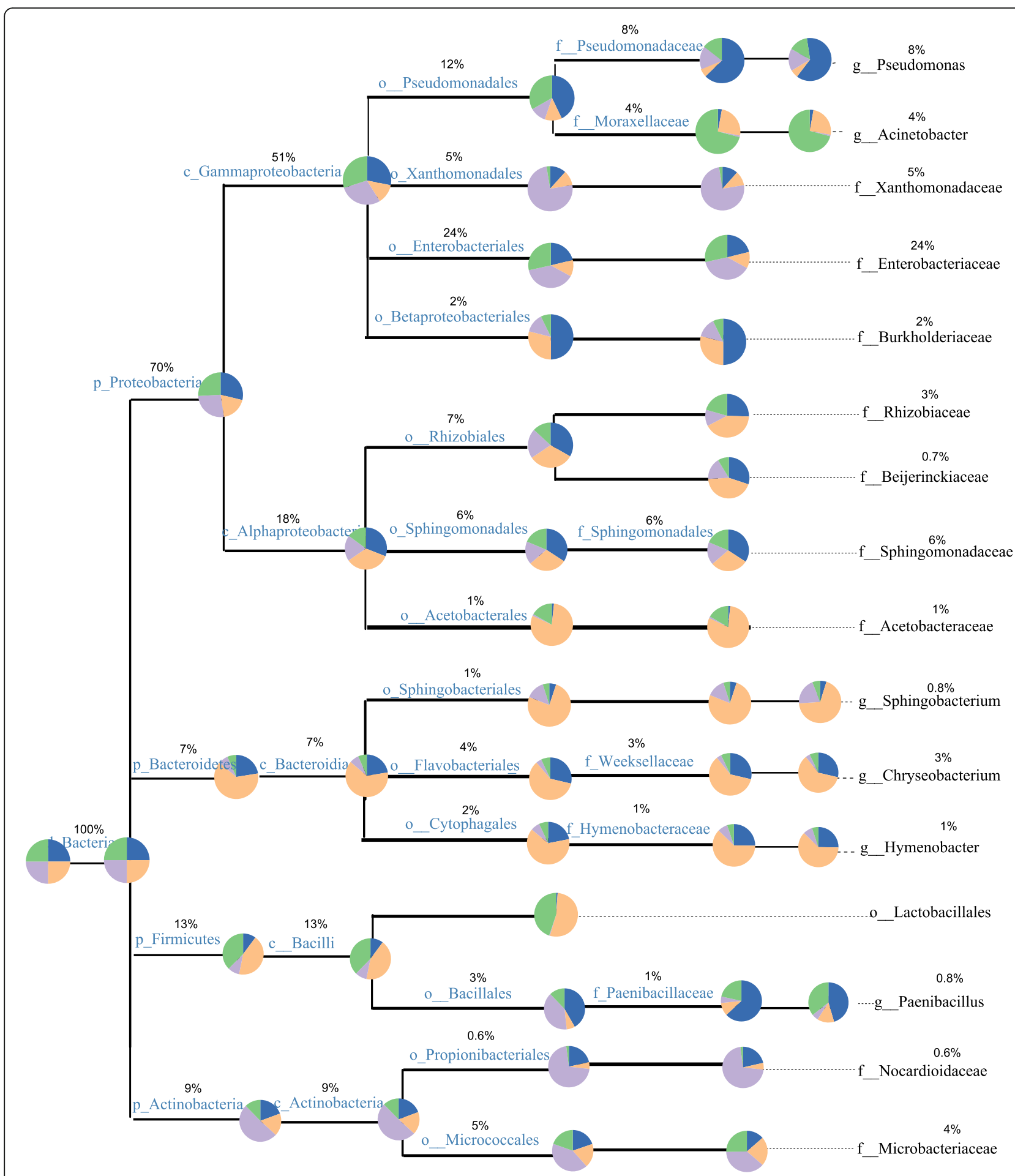

Fig. 2 The pie chart (threshold $0.5 \%$ ) of each branch node in the classification tree shows the proportion of the taxon in each group. The larger the sector area, the higher the abundance of the taxon in the group. The percentage above the taxon represents the percentage of the total bacteria

evolution (Faith 1992). Meanwhile, Pielou's evenness index represents species evenness (Pielou 1996) and Good's coverage index represents the coverage (Good
1958). Results were plotted into a boxplot using the $\mathrm{R}$ to exhibit the differences in diversity indices observed between different groups (Fig. 4). The microbial 


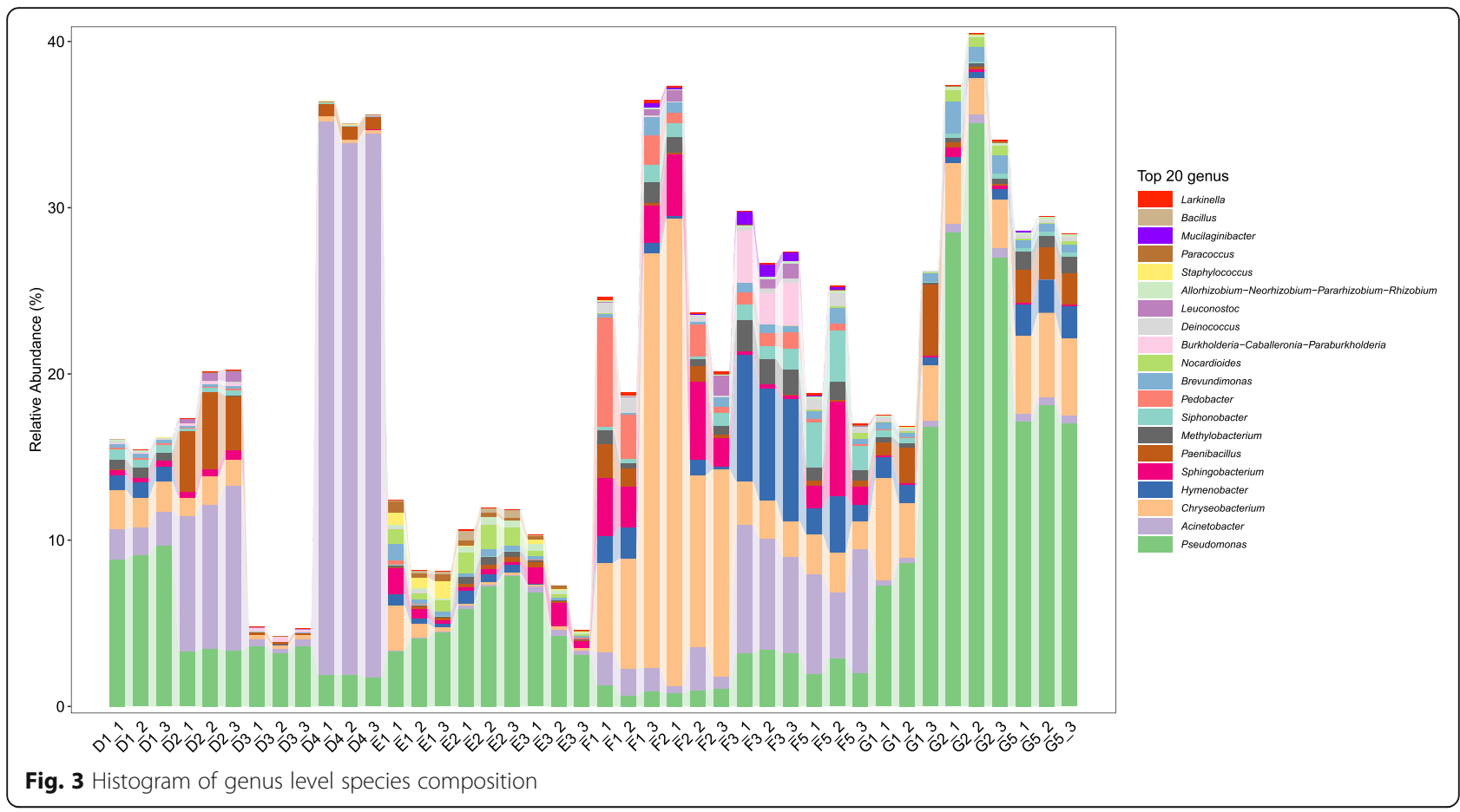

community richness, diversity, evenness, and evolutionary diversity of alfalfa (Fig. 4E, G) were higher than that of corn (Fig. 4D, F). However, the coverage of species in the microbial community of alfalfa was lower than that of corn. The microflora of alfalfa and corn collected in Xingtai had significant differences in community richness and evolutionary diversity. Meanwhile, the microflora of alfalfa and corn collected in Hengshui had highly significant differences in community richness, diversity, and evenness. Thus, the diversity of epiphytic bacterial community is significantly affected by plant species. All alpha diversity indices in the microflora of alfalfa collected in both sites were not significantly different. Alpha diversity indices, excluding evolutionary diversity, in the microflora of corn collected in Xingtai and Hengshui were not significantly different. We can conclude that the region has no significant effect on the diversity of epiphytic microbial communities.

\section{Beta diversity analysis}

The microbial communities in alfalfa and corn samples were compared using non-metric multidimensional scaling (NMDS) based on the weighted UniFrac distance (Lozupone and Knight 2005). Each point in the diagram represents a sample, and the different colored dots indicated different samples (Fig. 5). Samples were clustered according to their similarity, and the closer the distance between two points is, the more similar the two samples are. Alfalfa group samples aggregated in the NMDS analysis diagram, while the samples from the corn group were dispersed. Samples of corn (Fig. 5D, F) were similar and the samples of alfalfa (Fig. 5E, G) were similar. The results showed plant species affected the epiphytic bacterial communities, as compared with region.

\section{Species difference analysis and biomarker}

The number of ASV in groups D, E, F, and G was 6683, 8305, 6920, and 8080 respectively (Fig. 6). There are 545 ASVs in common, accounting for $2.34 \%$ of the total ASV.

We utilized the relative abundances of the top 50 genera to generate a heat map by heatmap package in $\mathrm{R}$ (Zhao et al. 2014). Heatmap shows a data matrix where coloring gives an overview of the numeric differences. In the genus-level species composition heat map for species clustering, red and blue patches indicate that the genera are more abundant and less abundant in a sample than the other sample. Lactic acid bacteria, such as those belonging in the genera Leuconostoc and Lactobacillus, have an important effect on silage fermentation and are among the top 50 genera in terms of relative abundance. Leuconostoc was mainly present in groups D2, F1, F2, and F3. Lactobacillus was mainly present in groups D1, D3, D4, F1, F2, F3, E1, E2, and E3 (Fig. 7). As presented in Fig. 7, groups F1 and F2 had higher abundance of Clostridium sensu stricto 1, which is harmful to fermentation.

We obtained the distribution of important species in each group by using the algorithm analysis of random forests (Breiman 2001) (Fig. 8). The abscissa represented 


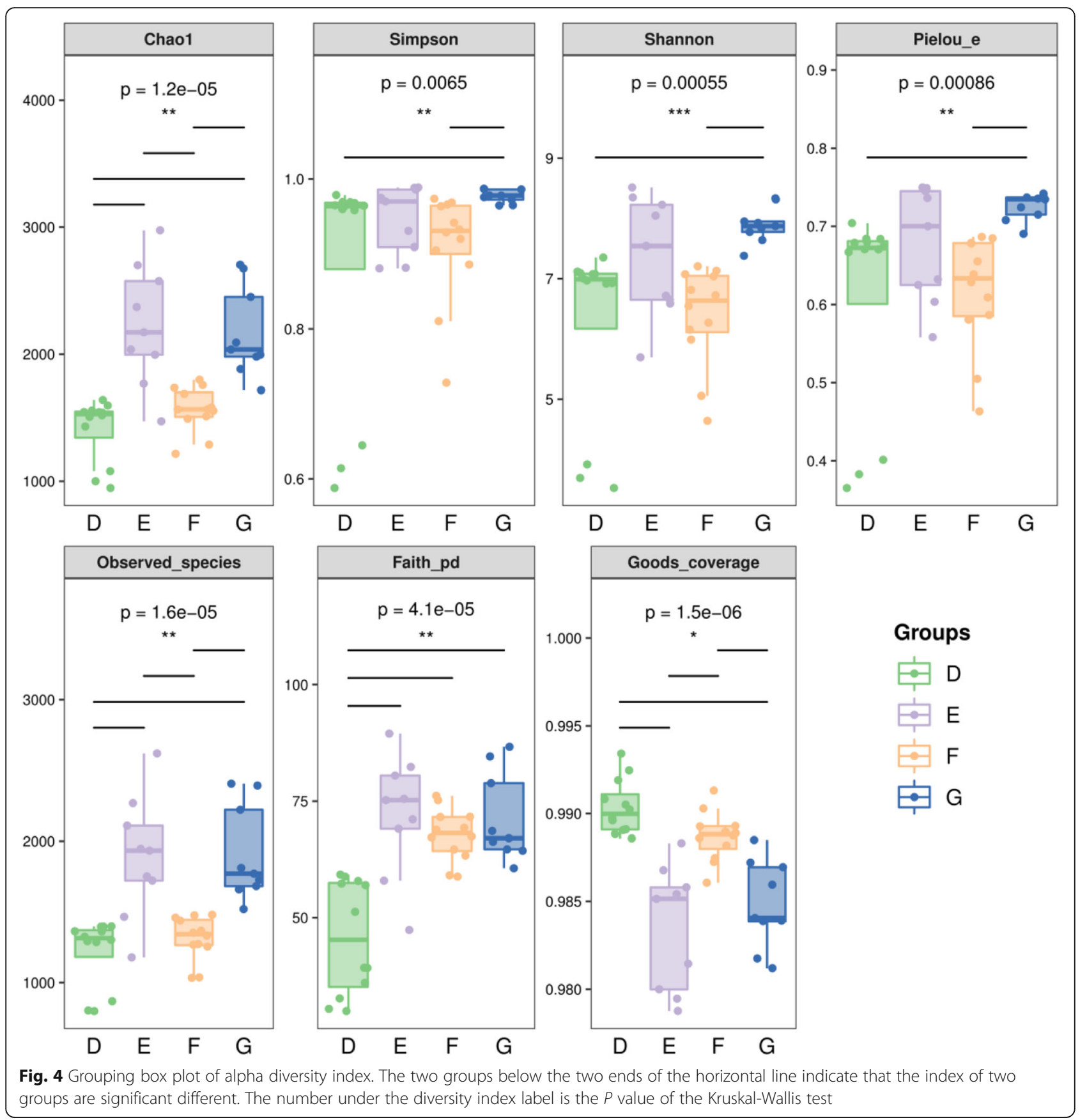

the importance of species to the classifier model, and the ordinate represented the taxon name at genus level. The importance of genus in shaping the bacterial community in each group decreases successively. These highly important genera, namely Pedobacter, Nocardioides, Chryseobacterium, Burkholderia-Caballeronia -Paraburkholderia, Paracoccus, Pseudomonas, Acinetobacter, Allorhizobium-Neorhizobium-Pararhizobium -Rhizobium, Larkinella, Mucilaginibacter, Sphingomonas, Brevundimonas, Siphonobacter, Methylobacterium,
Spirosoma, Hymenobacter, Bacillus, Actinomycetospora, Taibaiella, and Sphingobacterium, can be considered markers of differences in these groups. Most of these genera belong to Proteobacteria and Bacteroidetes. However, LAB, which have a positive impact on fermentation were not observed. The presence of Bacillus is worth noting. Bacillus causes the silage to deteriorate, leading to a rotten and smelly product. Bacillus was mainly observed SR4030 and Saidi 5 in Xingtai. We should choose crops with more LAB, less Bacillus and Clostridium, and 


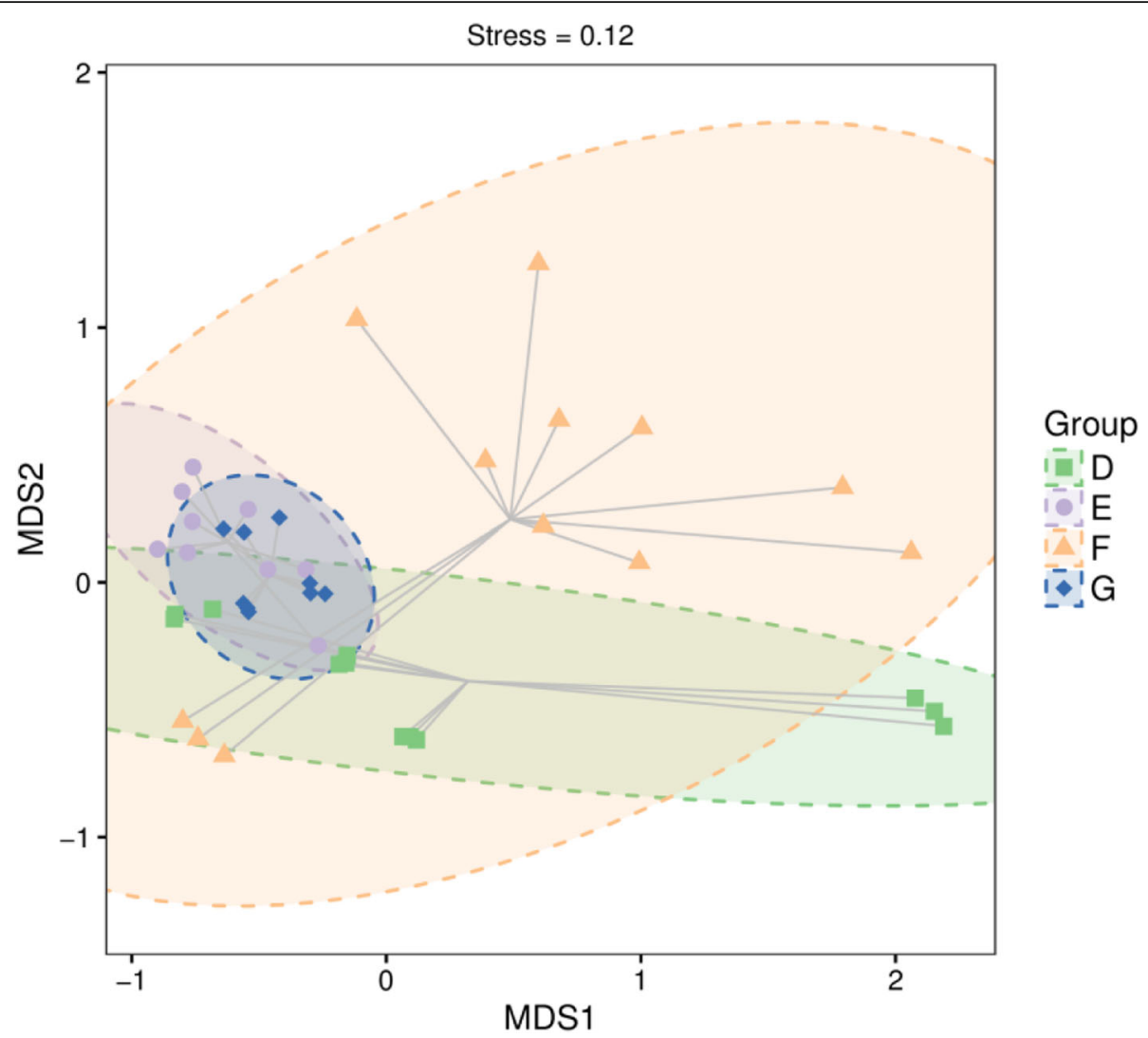

Fig. 5 NMDS analysis based on the weighted UniFrac distance

lower epiphytic microbial diversity for natural silage, because LAB on these crops may form dominant bacteria in a short time, reducing the loss of nutrients. Taking these factors into consideration, the epiphytic bacteria on Duobao No. 3 in Xingtai and Jinchu 100 in Hengshui may be better for natural silage. However, the content of moisture, protein, and sugar of plants also influence the quality of silage. We are going to do further study to choose the crops that are suitable for natural silage.

\section{Discussion}

Corn and alfalfa are widely used raw materials for natural silage. The epiphytic bacteria on crops substantially affect the quality of natural silage. Identifying the epiphytic microflora on forage can provide a scientific basis for effectively regulating the fermentation process of natural silage. There are only few detailed reports on the epiphytic microorganisms of corn and alfalfa. Most studies reported the microbes using the plate count method (Cai et al. 1999; Lin et al. 1992). Drouin et al. (2019) studied the epiphytic microflora on corn using highthroughput sequencing. However, these studies are not sufficiently detailed. In this study, the Illumina MiSeq/ NovaSeq system was used to analyze the diversity of epiphytic bacteria on corn and alfalfa.
Drouin et al. (2019) observed that the populations of bacteria on the corn samples collected immediately after inoculation, but prior to ensiling, were mainly composed of genera belonging to Proteobacteria $(56.4 \pm 1.5 \%)$, specifically in orders Pseudomonadales, Xanthomonadales, and Enterobacteriales; and to Bacteriodetes (37.4 \pm $1.7 \%)$, specifically in orders Sphingobacteriales and Flavobacteriales. In another study, $89.6 \%$ of the bacterial $16 \mathrm{~S}$ rRNA gene sequences were associated with the phylum Proteobacteria, and $8.1 \%$ were associated with the phylum Firmicutes; other phyla identified were Actinobacteria $(0.2 \%)$ and Bacteroidetes $(0.2 \%)$, before alfalfa ensiling (McGarvey et al. 2013). The populations of bacteria in the fresh corn and alfalfa samples in previous studies were mainly composed of genera belonging to Proteobacteria, Firmicutes, Actinobacteria, and Bacteroidetes, although their abundance varied slightly (Ali et al. 2020; Drouin et al. 2019; McGarvey et al. 2013). Most of the epiphytic bacteria of corn and alfalfa belong to Proteobacteria, and Enterobacteriaceae are the most predominant bacterial family on corn and alfalfa (Lin et al. 1992). These results are consistent with the present study. Proteobacteria was the most prevalent phylum in fresh corn, and the bacterial community of alfalfa was highly dominated by Firmicutes during the ensiling 


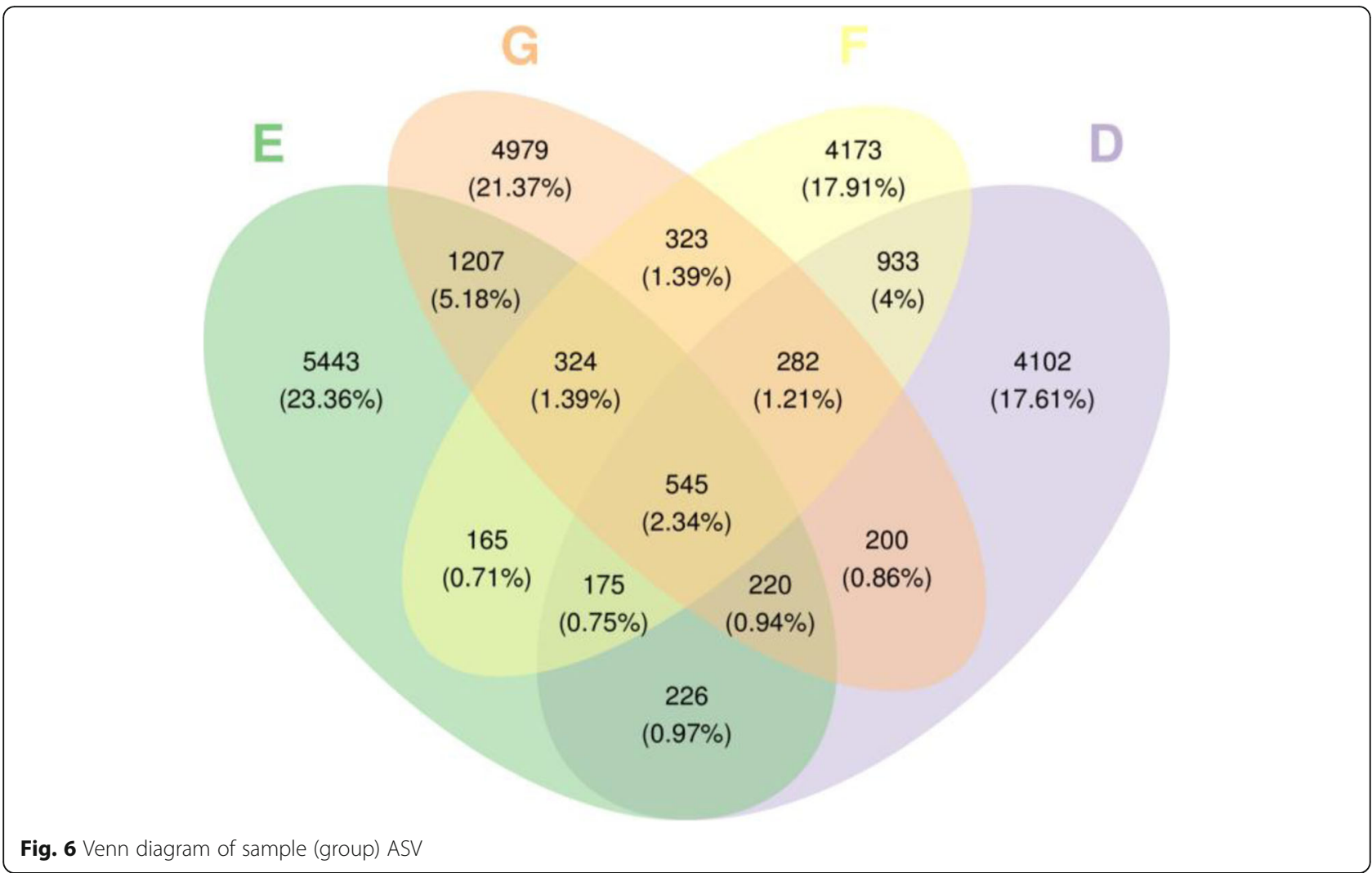

period, when the aerobic environment was changed to anaerobic. Moreover, the abundance of Firmicutes increased significantly (Drouin et al. 2019). Sequences affiliated with Lactobacillales were substantial contributors to the Firmicutes phylum order (Drouin et al. 2019). In our study, the main epiphytic bacterial composition in corn and alfalfa were consistent with the results of previous studies.

Our results suggest that the diversity of epiphytic bacterial communities is not affected by region, but it is significantly affected by plant species. This may also be associated with the similar environments of the two sites; thus, environment cannot affect the epiphytic microorganisms of the plants. However, the epiphytic microorganisms of forage are affected by forage species, stage of maturity, weather, mowing, field-wilting, chopping process humidity, solar radiation, plant surface structure, and plant nutrient distribution (Lin et al. 1992; Bai 2011). This may be the reason the species and number of epiphytic bacteria in different raw silage materials were quite variable in the present study.

The diversity and richness of the epiphytic bacterial community of alfalfa were significantly higher than those of corn. The Shannon diversity index of corn and alfalfa was between 5 and 9, higher than those reported by Drouin et al. (2019). The Shannon diversity index was higher for the fresh corn samples, with a mean of $5.26 \pm$
0.27 , in the previous study (Drouin et al. 2019). We observed LAB, such as Leuconostoc and Lactobacillus, in the top 50 genera in average abundance. Several studies have shown that corn has higher LAB composition than other crops. For example, the number of LAB on the surface of corn was twice than that of sorghum and alfalfa, and 20 times than that of ryegrass (Cai et al. 1999). Meanwhile, the total number of LAB on corn is seven times than that of grass and 15 times than that of clover (Kasmaei et al. 2017). The lactic acid and acetic acid contents of silage corn silage corn, elephant grass, and sugarcane tops were significantly increased by adding the epiphytic microorganisms of corn straw, and the aerobic stability of elephant grass silage was positively affected (Huang et al. 2020). Kasmaei et al. (2017) observed that the increase in lactic acid and acetic acid content in corn straw silage by epiphytic microorganisms may be related to the abundance of Lactococcus and Leuconostoc (Kasmaei et al. 2017). Crops with more LAB are more suitable for natural silage (Lin et al. 1992). Thus, corn may be a better source of natural silage than alfalfa.

There are several undesirable microorganisms, such as anaerobic bacilli of the genus Clostridium, aerobic bacteria of the genus Bacillus, coliform bacilli, in the fermentation process and silage quality (Fabiszewska et al. 2019). We observed that Duobao No. 3 and Shengrui 


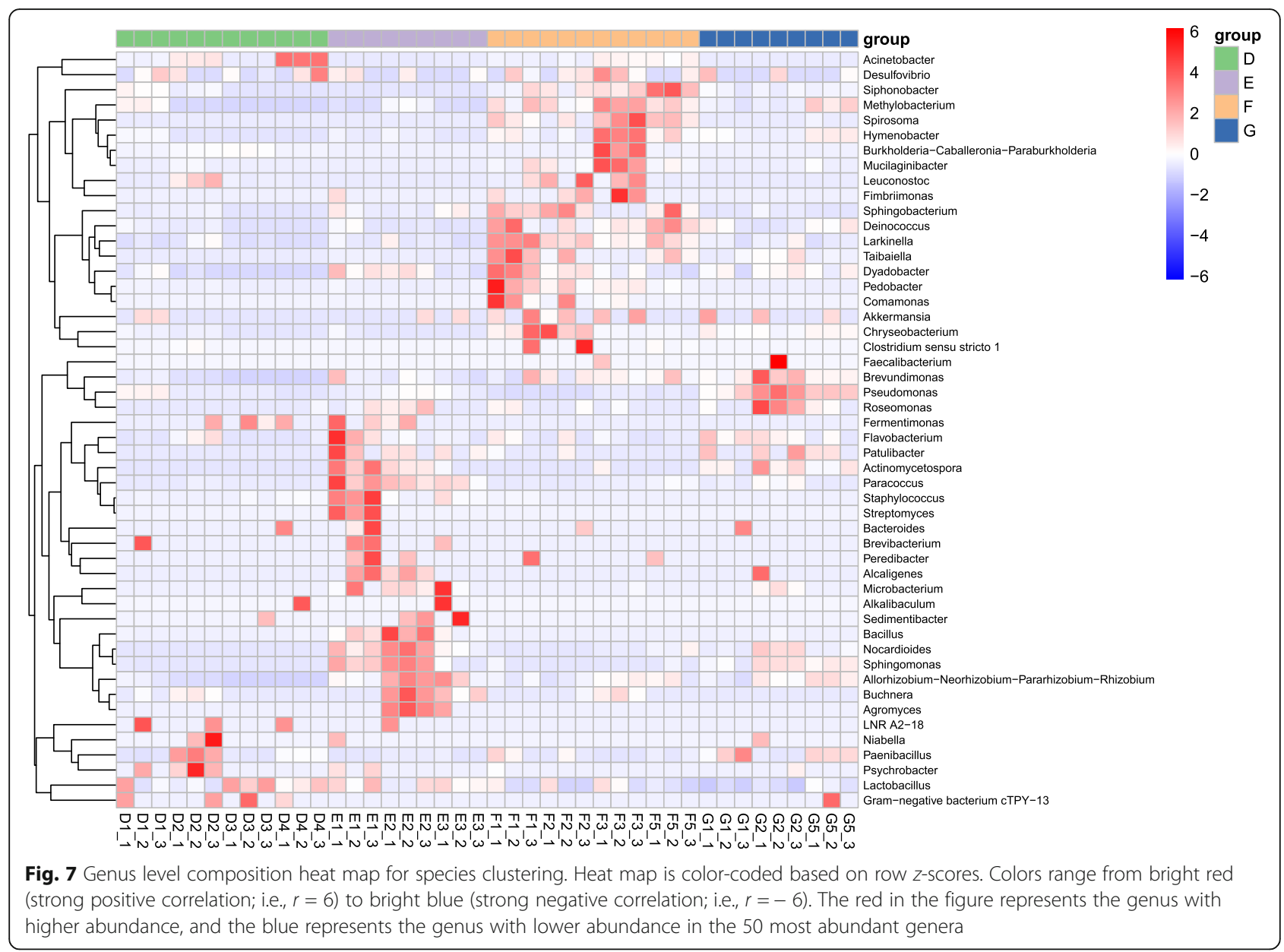

565 in Hengshui have more Clostridium sensu stricto 1, while Bacillus was mainly observed in SR4030 and Saidi 5 in Xingtai. Tao et al. used Illumina Miseq highthroughput sequencing technology to analyze the change in microflora structure in corn stalk before and after natural silage. The results showed that the number of bacteria belonging to Firmicutes, Bacilli, Lactobasubcillales, Lactobacillaceae, Pediococcus, and Lactobacillus increased, while Proteobacteria and Enterobacteriace decreased (Tao and Diao 2016). Moreover, it was

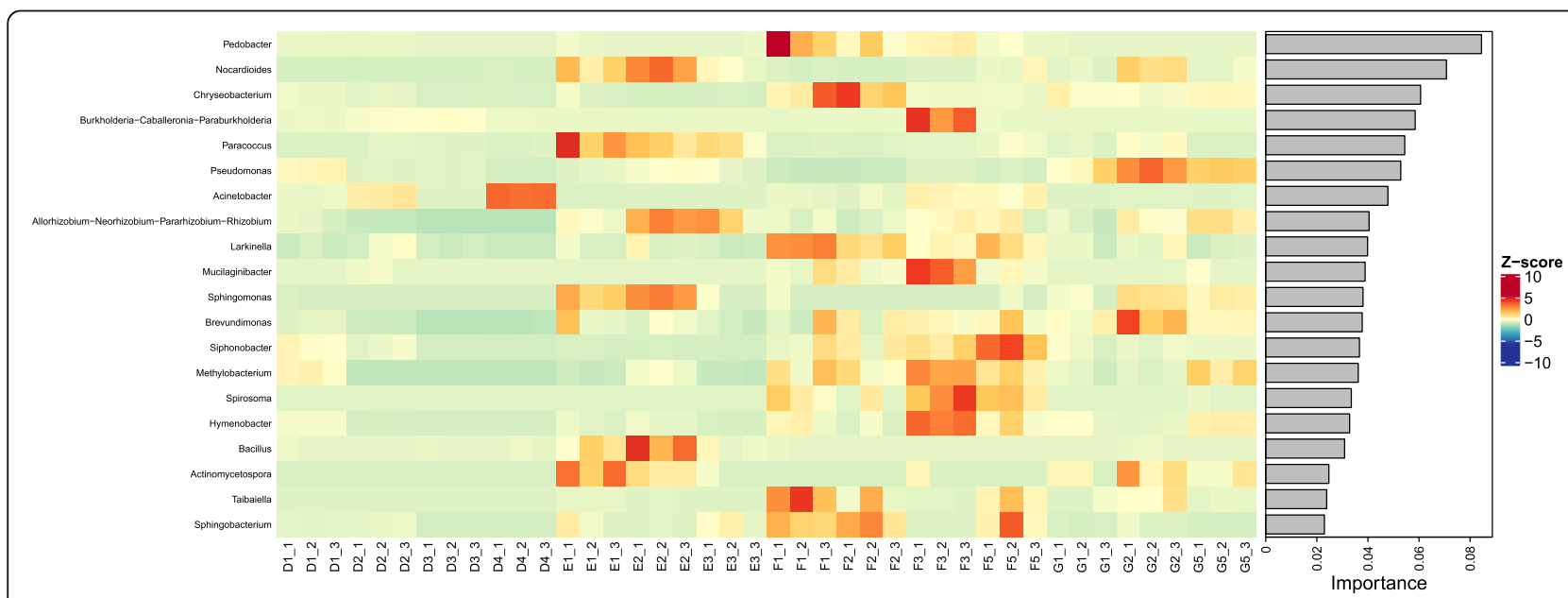

Fig. 8 Genus heat map of top 20 importance 
revealed that the aerobic stability was increased by $66 \sim$ $312 \mathrm{~h}$ after the quantity of Clostridium in silage decreased in the aerobic stability test of silage (Jatkauskas and Vrotniakiene 2013).

Epiphytic bacteria on crops run throughout the whole fermentation process, affecting the quality of the natural silage. These bacterial communities also have a succession process, indicating that the microorganism on the forage greatly affect the quality of the natural silage. However, the structure of silage microbial community and its mechanism of succession are still unclear, and more information is needed to reveal this complex fermentation process (Xu et al. 2017).

\section{Conclusion}

In summary, the dominant phyla were Proteobacteria (70\%), Firmicutes (13\%), Actinobacteria (9\%), and Bacteroidetes $(7 \%)$ on corn and alfalfa in Xingtai and Hengshui. At the genus level, Pseudomonas (8\%), Acinetobacter (4\%), Chryseobacterium (3\%), and Hymenobacter (1\%) were the main bacteria genera. Enterobacteriaceae are the most predominant bacteria on corn and alfalfa. This study showed that the diversity of epiphytic bacterial community was significantly affected by plant species, but not by region. The composition richness and diversity of microbe of alfalfa are higher than that of corn in both Xingtai and Hengshui. Duobao No. 3 in Xingtai and Jinchu 100 in Hengshui may be more suitable for natural silage than other samples we collected considering the influence of epiphytic bacteria on natural silage. But we still need further study to determine the crops that are suitable for natural silage.

\section{Acknowledgements}

This study was funded by the Hebei Grass Industry Innovation team of Modern Agricultural Industry Technology System (HBCT 2018050204) and Study on the key techniques of improving the quality of high quality forage silage (19222702D).

\section{Authors' contributions}

H.T. (Professor) planned and designed this study. M.W. (graduate student) analyzed data and wrote this article. All authors read and approved the final manuscript.

\section{Funding}

Not applicable.

\section{Availability of data and materials}

Data is available under request.

\section{Declarations}

Ethics approval and consent to participate

Not applicable

\section{Consent for publication}

Not applicable.

\section{Competing interests}

The authors declare they have no conflict of interests.

\section{Author details}

${ }^{1}$ School of Life Sciences, Hebei University, Baoding 071002, People's Republic of China. ${ }^{2}$ Key Laboratory of Microbial Diversity Research and Application of Hebei Province, Engineering Laboratory of Microbial Breeding and Preservation of Hebei Province, Institute of Life Sciences and Green Development, Baoding 071002, People's Republic of China. ${ }^{3}$ Hebei Research Center for Geoanalysis, No. 180 Wusi East Road, Baoding City 071002, Hebei Province, People's Republic of China.

Received: 26 May 2021 Accepted: 28 August 2021

Published online: 20 September 2021

\section{References}

Ali N, Wang SR, Zhao J, Dong ZH, Li JF, Nazar M, Shao T (2020) Microbial diversity and fermentation profile of red clover silage inoculated with reconstituted indigenous and exogenous epiphytic microbiota. Bioresour Technol 10: 123606

Bai Y (2011) Studies on the foliar microflora of bamboo forests in Sichuan. Sichuan Agricultural University, Dissertation, Yaan

Bolyen E, Rideout JR, Dillon MR, Bokulich NA, Abnet CC, Al-Ghalith GA (2018) QIIME 2: reproducible, interactive, scalable, and extensible microbiome data science. PeerJ 6:e27295V2 Preprints

Breiman L (2001) Random forests. Mach Learn 45(1):5-32. https://doi.org/10.1 023/A:1010933404324

Cai Y, Kumai S, Ogawa M, Benno Y, Nakase T (1999) Characterization and identification of Pediococcus species isolated from forage crops and their application for silage preparation. Appl Environ Microbiol 65(7):2901-2906. https://doi.org/10.1128/AEM.65.7.2901-2906.1999

Callahan BJ, McMurdie PJ, Rosen MJ, Han AW, Johnson AJA, Holmes SP (2016) DADA2: high-resolution sample inference from Illumina amplicon data. Nat Methods 13(7):581-583. https://doi.org/10.1038/nmeth.3869

Chao A (1984) Nonparametric estimation of the number of classes in a population. Scand J Stat 11:265-227

Drouin P, Tremblay J, Chaucheyras-Durand F (2019) Dynamic succession of microbiota during ensiling of whole plant corn following inoculation with Lactobacillus buchneri and Lactobacillus hilgardii alone or in combination. Microorganisms 7(12):595. https://doi.org/10.3390/microorganisms7120595

Fabiszewska AU, Zielińska KJ, Wróbel B (2019) Trends in designing microbial silage quality by biotechnological methods using lactic acid bacteria inoculants: a minireview. World J Microbiol Biotechnol 35(5):76. https://doi. org/10.1007/s11274-019-2649-2

Faith DP (1992) Conservation evaluation and phylogenetic diversity. Biol Conserv 61(1):1-10. https://doi.org/10.1016/0006-3207(92)91201-3

Gharechahi J, Kharazian ZA, Sarikhan S, Jouzani GS, Aghdasi M, Salekdeh GH (2017) The dynamics of the bacterial communities developed in maize silage. Microb Biotechnol 10(6):1663-1676. https://doi.org/10.1111/1751-7915.12751

Ginestet C (2011) Ggplot2: elegant graphics for data analysis. J R Stat Soc 174(1): 245-246. https://doi.org/10.1111/j.1467-985X.2010.00676_9.X

Good IJ (1958) The population frequency of species and the estimation of the population parameters. Biometrics 40:237-246

Huang F, Li H, Wang K, Zhou XK, Gu Q, Zhang L, Zhang J, Yi SY, Zou CX (2020) Effects of epiphytic microorganisms on fermentation quality and aerobic stability of silage. Ann Nutr 32:5976-5984

Huang F, Zang L, Zhou B, Zou CX (2019) Research process in silage microorganism and its effect on silage aerobic stability. Ann Nutr 31:82-89

Jatkauskas J, Vrotniakiene V (2013) Evaluation of fermentation parameters, microbiological composition and aerobic stability of grass and whole crop maize silages treated with microbial inoculants. Zemdirbyste 100(2):143-150. https://doi.org/10.13080/z-a.2013.100.018

Kasmaei KM, Dicksved J, Sprndly R, Uden P (2017) Separating the effects of forage source and field microbiota on silage fermentation quality and aerobic stability. Grass Forage Sci 72:281-289

Lin C, Bolsen KK, Brent BE, Hart RA, Dickerson JT, Feyerherm AM, Aimutis WR (1992) Epiphytic microflora on alfalfa and whole-plant corn. J Dairy Sci 75(9): 2484-2493. https://doi.org/10.3168/jds.S0022-0302(92)78010-2

Lozupone C, Knight R (2005) UniFrac: a new phylogenetic method for comparing microbial communities. Appl Environ Microbiol 71(12):8228-8235. https://doi. org/10.1128/AEM.71.12.8228-8235.2005

McGarvey JA, Franco RB, Palumbo JD, Hnasko R, Stanker L, Mitloehner FM (2013) Bacterial population dynamics during the ensiling of medicago sativa (alfalfa) 
and subsequent exposure to air. J Appl Microbiol 114(6):1661-1670. https:// doi.org/10.1111/jam.12179

Pielou EC (1996) The measurement of diversity in different types of biological collections. J Theor Biol 13:131-144

Rognes T, Flouri T, Nichols B, Quince C, Mahé F (2016) VSEARCH: a versatile open source tool for metagenomics. PeerJ 4:e2584. https://doi.org/10.771 7/peerj.2584

Shang ZD, Tan ZK, Li JK, Zhuo G, Li F, Wang HH, Xie GP, Liu SZ (2019) Effects of different planting seasons on the fermentation quality and microbial diversity of corn silage in Tibet. Acta Agrestia Sin 27:488-496

Simpson EH (1949) Measurement of Diversity. Nature 163(4148):688. https://doi. org/10.1038/163688a0

Tao L, Diao QY (2016) Effects of ensiling on quality and bacteria composition of corn stalk. Ann Nutr 28:198-207

Xie XH, Liu N, Yang B, Yu CZ, Zhang OY, Zheng XL, Xu L, Li R, Liu JS (2016) Comparison of microbial community in hydrolysis acidification reactor depending on different structure dyes by Illumina MiSeq sequencing. Int Biodeterior Biodegradation 111:14-21. https://doi.org/10.1016/j.ibiod.2016. 04.004

Xu DM, Zhang P, Ke WC, Guo XS (2017) Research Process in Silage Microorganism and Its Effects on Silage Quality. Acta Agrestia Sin 25:460-465

Yu GC, Smith DK, Zhu HC, Guan Y, Lam TT (2017) GGTREE: an R package for visualization and annotation of phylogenetic trees with their covariates and other associated data. Methods Ecol Evol 8(1):28-36. https://doi.org/1 $0.1111 / 2041-210 X .12628$

Zhang HJ (2011) The dynamic changes of microbial flora in forage silage and identification and screening of lactic acid bacteria species isolated from forage silage. Dissertation, Chinese Academy of Agricultural Sciences

Zhang HJ, Yu Z, Wang L, Cai YM, Li F, Tao Y, Sun ZQ (2011) Isolation and identification of lactic acid bacteria from silage and filtering of excellent strains. Acta Agrestia Sin 19:137-141

Zhao S, Guo Y, Sheng Q, Shyr Y (2014) Advanced heat map and clustering analysis using heatmap3. Biomed Res Int 2014:986048

\section{Publisher's Note}

Springer Nature remains neutral with regard to jurisdictional claims in published maps and institutional affiliations.

Ready to submit your research? Choose BMC and benefit from:

- fast, convenient online submission

- thorough peer review by experienced researchers in your field

- rapid publication on acceptance

- support for research data, including large and complex data types

- gold Open Access which fosters wider collaboration and increased citations

- maximum visibility for your research: over $100 \mathrm{M}$ website views per year

At $\mathrm{BMC}$, research is always in progress.

Learn more biomedcentral.com/submissions 